\title{
How Have Irish Parliamentarians Adapted to the Age of Web 2.0?
}

\section{Neil, Collins}

2017-12

Neil , C \& Chen , J Y-W 2017 , ' How Have Irish Parliamentarians Adapted to the Age of Web 2.0? ' , International journal of e-politics , vol. 8 , no. 4 , pp. 21-33 . https://doi.org/10.4018/lJEP.2017100102

http://hdl.handle.net/10138/328248

https://doi.org/10.4018/lJEP.2017100102

acceptedVersion

Downloaded from Helda, University of Helsinki institutional repository.

This is an electronic reprint of the original article.

This reprint may differ from the original in pagination and typographic detail.

Please cite the original version. 


\title{
How Have Irish Parliamentarians Adapted to the Age of Web 2.0?
}

\author{
Neil Collins \\ University College Cork, Ireland/ Nazarbayev University, Kazakhstan \\ Yu-Wen Chen
}

University of Helsinki

\section{ABSTRACT}

This study explores the engagement of members of the Irish lower parliamentary chamber, the Teachta Dála (TD), with Web 2.0 technologies. Content analysis is employed to evaluate TDs' websites. While conducting the website-feature analysis, the authors look at three dimensions of each TD's website: information content, interaction tools and politician's activities on the web. The authors find that Irish parliamentarians embed themselves online mainly to catch up with the trends in the cyber age. Websites allow them to market themselves and increase visibility. But given that the offering of information is the prime aim, their usage of the Internet is still largely based on the paradigm of Web 1.0. A more accurate way to depict this phenomenon is that Irish politicians' Internet usage is actually in the mode of Web 1.5 in which some interactive and participatory space is generated with the idea that the cyberspace should encourage citizen participation.

Keywords: Web 2.0, Website-feature Analysis, Ireland, Teachta Dála (TD) 


\section{INTRODUCTION}

In 2010, Lilleker and Jackson evaluated the impact of Web 2.0 on the UK General

Election of that year. They found that British political parties are underachieving with regard to maximizing the interactive potential of Web 2.0 to encourage participation by the electorate. This is in contrast to Obama's campaign in which citizen participation "in the forms of sharing and acting as an advocate online" through offering feedback to the campaign was encouraged (Lilleker \& Jackson, 2010, p. 71). Lilleker and Jackson's finding is in line with the broader debate on the impact of social media on the pattern of political competition, in which much is made of the contrast between candidate-focused election systems (e.g. US), which are assumed to encourage campaign innovation, and those with strong parties (e.g. UK), which are presented as lagging behind in adopting new methodologies (see also Strandberg, 2013).

In this article, the use of Web 2.0 by politicians in a system which is both candidate-centric but with strong party orchestration is analysed in the context of the mid-point in the electoral cycle (Williamson, 2009, p. 514), taken here to mean a period of politics considered as 'normal' (Abney et al., 2013), or, in other words, a non-election period. ${ }^{1}$ The research locale is the Republic of Ireland, ${ }^{2}$ where the electoral system and political culture foster both strong intra- and inter-party competition (Collins, 2004). The question to be answered is whether Web 2.0 is a game changer in the Irish context, facilitating quintessentially new political interaction between politicians and their electorate, or simply a means of expediting established patterns of behaviour (Schlozman, Verba, \& Brady, 2010, p. 489). It is, of course, important to note that Web 2.0 denotes cumulative modifications to the Internet since Web 1.0. Primarily, Web 2.0 facilitates dynamic interactions rather than 
one-way information flows and is not limited to browsing content. It is hoped that this case study of Ireland can contribute empirical evidence to the current debate over whether Web 2.0 can change the fundamental ways of how politics are played in this cyber age.

If information and communication technologies (ICTs) have offered a new way for Irish politicians to interact with constituents, this would imply that the discussion, negotiation and formation of policies could take place online as well. Although online discussions are not about hard policymaking, the ideas generated in online debates could help representatives to garner constituents' views over certain issues and policies and this might affect the agenda setting, formation, interpretation and implementation of policies later.

In Ireland, as elsewhere, the core imperative for most politicians is re-election, and this tutors their behaviour in a direct way, even allowing for assumed inclinations towards public service and ideological conviction. Obviously, those whom Barber (1965) termed the 'advertisers' and the 'reluctant' may stand outside the larger group, but even their conduct may need to meet the mainstream public expectation.

Striking ideological differences do not mark political competition between the parties in the Irish parliament. The left-right cleavage is not pronounced and the traditionally large parties can be characterized as centre/right (Marsh, Farrell, \& McElroy, 2017). Fianna Fáil and Fine Gael, the two largest parties, trace their roots to the Civil War of 1922-3 (Collins, 2004). Although the economic crisis of 2008 was particularly damaging to Fianna Fáil, traditionally the largest Irish party, it has since practically recovered its position, according to the opinion polls. ${ }^{3}$ All Irish governments since 1989 have been coalitions. For the individual parliamentarian, the major electoral very often comes from candidates of the same party or, occasionally, 
'independents' campaigning on particularly contentious local issues. Each constituency returns three to five TDs. Irish politicians, therefore, spend a lot of time and resources on managing constituency affairs in order to cultivate votes (Butler \& Collins, 2001), sometimes even at the expense of their role as national lawmakers (McGraw, 2016; Martin, 2013; O’Leary, 2011).

It may be assumed that this is particularly the case for deputies whose seats are less secure, but in the Dáil, which is the lower but principal chamber of the Irish legislature, electorally secure incumbents are few in number. ${ }^{4}$ Although recent elections have been marked by changes in parliamentary personnel, in many ways the essentials of how Irish politics operates has not altered much (Marsh et al., 2017; Marsh \& Mikhaylov, 2014).

In 1976, the role of the members of the Dáil, the TDs, was described by two scholars as being cantered on influencing the decisions of civil servants, 'pulling strings', and acting as confidantes for their constituents ('hearing confessions'). Bax (1976) and Sacks (1976) ascribed differing impacts to these functions, but the brokerage style they described was accepted as reasonably accurate. Both authors confirmed Chubb's (1963) famous description of the TD's role as 'persecuting civil servants' (Butler \& Collins, 2001). The patterns have changed little, as revealed by recent publications: "the demand for constituency service runs deep in Irish society" (Marsh et al., 2017, p. 161).

With regards the interest of this study, Murphy (2013) reports that Irish parliamentarians appear to be willing to be engaged with Web 2.0, but she did not examine further TDs' exact Web 2.0 usage.

The next section will begin by exploring how Web 2.0 is believed and empirically found to have affected politics in the international context. This will be 
followed by an introduction to the research method and data. Section four presents a website feature analysis of TDs to see how they have actually explored and made use of the potentials of Web 2.0. The data enables the examination of 88 TDs' personal websites. This is followed by section five in which a comparison between TDs' performance across websites, Twitter and Facebook is made.

\section{LITERATURE REVIEW: NEW TECHNOLOGIES AND POLITICS}

Web 2.0 technologies have allowed a more interactive, networked and conversational way of communication that transcends borders and cultures (Lilleker \& Jackson, 2010). With Web 2.0 technologies becoming more influential, it is no surprise that more and more politicians are using this new form of media to gain election support. A plethora of studies has been conducted to address the innovations and new campaign techniques that US politicians have used to promote themselves in "an individualized and candidate-cantered political system" (Hermans \& Vergeer, 2013, p. 74). A quintessential example in point is Obama's presidential campaign, which has generated much academic inquiry because it was seen as innovative and being able to alter the relationship between the mass media and political campaigns in a way which had not been seen to any real effective extent in America before. The 2016 presidential election also afforded a prominent role to social media (Scacco \& Coe, 2017). The social media allowed a campaigner to interact one-on-one with potential voters without knocking on every door in the country. To convey his message unedited by any media giants, Obama has personal accounts on Web 2.0 platforms such as Facebook, Twitter, MySpace, podcasts, as well as YouTube (Harfoush, 2009, p. xiii). In other words, Obama not only advanced the position of his campaign but also blasted the use of Web 2.0 into the forefront of political campaigning worldwide. 
In fact, not only Obama, but also most members of the US Senate and Congresses now maintain an official Twitter account. President Trump is an avid user of Twitter (Ott, 2017). To add to the phenomenon of Web 2.0, the birth of the smartphone industry had made social media mobile. Candidates were now expected to interact with the online community on a twenty-four-hour basis. Broadcast news stations (old media) now regularly refer to how a candidate's actions or speeches are received on Web 2.0 platforms.

On the other side of the Atlantic, politicians are also picking up this trend, but there are variations of Web 2.0 usage among politicians in European countries. Weblogs, for instance, have been used by major parties and many candidates in Germany for the Bundestag elections, although they do not seem to have caught the attention of most citizens (Hoffmann \& Suphan, 2017; Albrecht, Lübcke, \& Hartig-Perschke, 2007). In the cross-country comparative analysis of Vergeer, Hermans, and Cunha (2013) and Hermans and Vergeer (2013), Ireland stood out as one of the few European countries where parties and politicians use websites extensively (Vergeer et al., 2013, p. 138) and most of the e-campaigns manifest the politicians' efforts to 'personalize' themselves professionally and/or privately (Hermans \& Vergeer, 2013, p. 81). The details of how Irish websites are structured for these purposes, however, remain to be explored.

It is crucial to note the extent to which previous 'new' technologies were expected to change politicians' behaviour (Farrell \& Webb, 2000; Listen et al., 2013). Farrell and Webb (2000) were clear that:

The 'Television Age' ushered in nationalized campaigning, with an emphasis on the broadcasting of single, coordinated nationwide messages. In sharp contrast, the 'Digital Age' looks like causing something of a reversion in the culture of campaigning back towards more focused, localized, targeted communication ... 
[T] he potential of these new technologies to impact significantly on the future of political campaigns cannot be overlooked. (p. 114)

In relation to the nature of the changing pattern of communication brought about by social media, Standage (2013) argues that in historical terms, it is top-down, centralized mass distribution of information that is the deviation. Until the Industrial Revolution, individual opinion circulated from person to person; today's social media marks the return to a historically dominant pattern (Standage, 2013). Although Standage might be right to contend that social media enables the return to past patterns of horizontal diffusion of messages, it is vital to acknowledge that there are differences between the patterns of diffusions between those in the past and today. Historical patterns were more confined geographically, while today's diffusion can move beyond wider territorial boundaries and sometimes even become transnational. A study of parliamentarians' use of social media in Britain asserts:

... there is a tangible shift in the balance of power as constituents, single-issue groups and other interested external parties are able to create new channels of engagement quickly and cheaply, providing considerable reach and demonstrably influencing public and political opinion. (Williamson, 2009, p. 514)

The voters, however, are much more inclined to use social media for conversations on sport or entertainment (Fuchs, 2017). As Jensen (2017) says, in relation to UK voters in general, the "empowering uses of Twitter are fairly marginal" (p. 23).

Overall, a common theme in the examples and commentary cited here is that

Web 2.0 tools do not change the fundamental ways in which politics is conducted, although it is increasingly used by professionals in politics. This also appears to be observable in non-democracies, as noted by Chen (2012 and 2013), where the Internet does not effectively alter the relationship between the state and the society in China. 
What the Internet does change, however, is the cost and benefits of the actors' calculations for their behaviours (Collins \& Cottey, 2012; Chen, 2013). Some state and societal actors in China see the benefits of using Web 2.0 technologies for their social and political aims. In such a context, Web 2.0 tools are used as a kind of extended means for them to achieve their goals. The fundamental structures of how the Chinese state and society interact with each other, nonetheless, remain largely unaltered (Chen, 2012).

In democracies as well as in non-democracies, for those with access to it, it has lowered some of the barriers to political activity by reducing the costs and by removing any constraints on when and where it takes place. In Western liberal democracies like the one under investigation in this paper, campaign donations, contacts with public officials, accessing information and forming political groups are all now very much easier, cheaper and less spatially bound. The question remains, however, if and how the experience of politics has essentially changed for either politicians or citizens.

Strandberg (2013), in his study of the Finnish 2011 General Election, suggests that those who avail of it make little impact (p. 1329). This lack of impact may dismay advocates of greater democratic engagement (Schlozman et al., 2010, p. 489), but it does also point to the atypical nature of political discourse during formal election campaigns when the resistance to new data may be greatest (Vromen, 2017; Hall et al., 2013; Wicklund \& Brehm, 1976).

It is also interesting to note that one generalization stands out: where online access is available, the young are more knowledgeable about and have a higher propensity to use Web 2.0 tools. Examining 'Generation Z' ${ }^{5}$ in Indonesia, for example, Samodra and Mariani (2013) conclude that users' 'perceived usefulness' of 
Web 2.0 tools with an indirect influence of their 'perceived ease-of-use' of these tools could facilitate the diffusion of these technologies (p. 127). In Ireland, outcomes of indepth interviews and focus group studies interestingly suggest that while Generation $\mathrm{Z}$ thinks it is good for political parties to utilize online social networking tools to have contact with their age group, they still prefer to see public representatives at their doorstep (Lynch \& Hogan, 2012, pp. 95-96).

Previous studies have discussed the perceptions and preferences of constituents in Ireland in this regard. This study, however, focuses on understanding Irish TDs' engagement with Web 2.0 technologies. Data will be presented on how Irish parliamentarians exploit the functions and potentials of Web 2.0 by mainly looking at the content and design of their websites. The research method and design are clarified in the next section.

\section{METHODOLOGY}

Content analysis is employed to evaluate the websites of members of the Dáil. Data from TDs' personal websites were compiled from July 15 to 25, 2013. This period was taken to epitomize 'normal' time with the Dáil taking its summer break on July 18. In the period immediately before the adjournment, the most controversial issues in politics had been a bill to adjust the existing abortion legislation in the light of a contentious court case; a proposal for a referendum to abolish the upper parliamentary chamber, Seanad Éireann; and, a few cases of 'unparliamentary behaviour' in the Dáil.

While each of these issues caused some controversy, none looked capable of precipitating an election, ministerial resignation or significant shifts in public opinion. In the same period, ministers were able to point to signs of economic recovery and give assurances regarding the level of social welfare provision. 
The authors initially surveyed all 166 Irish TDs. This includes the websites of Michael McGrath and Eamon O'Cuiv, which were under construction during the period when the researchers were collecting the data. From the total TDs, 76 do not have personal websites. Hence, in total, the authors concentrate on the remaining 88 TDs' personal websites.

While conducting the website-feature analysis, the authors look at three dimensions of the TD's websites: information content (IC), interaction tools (IT) and politician's activities on the web (PAW) (Lilleker \& Jackson, 2013; Vaccari, 2008). These contents were assigned scores, and the average score that each website obtained was calculated afterwards.

IC was measured by examining how many of the following ten features exist on each TD's website: general issues, information on specific topic areas (e.g. immigration and agriculture), speeches, newsletters, newsletter archives, FAQs, events calendar, videos, media release, and candidate profiles. Each TD's website was given a score on a scale of 0 to 5 . Websites that contain at least nine of the ten aforementioned features were coded 5. Websites that contain seven to eight of the ten features were coded 4 . The same logic applies to the rest of the coding scheme.

IT features the following variables: search tool, subscription, volunteering, donation, online contact, comments, link with social media (e.g. YouTube), ability to share content with other social media platforms, online membership, and site map. The coding for this variable is the same as the coding for IC.

PAW was measured by two variables. The authors first assigned a score for each variable, and then they calculated the average score for the two variables. The first variable is the number of updates between March 1 and July 31, 2013, over five months in total. Also, the authors observed the latest month in which the website had 
been updated. For the first variable (number of updates in five months starting from March 1, 2013), the authors assigned a score on a scale of 0 to 5 ( $0=$ zero updates, 1 =1-20 updates, $2=21-40$ updates, $3=41-60$ updates, $4=61-80$ updates, $5=81-100$ updates).

For the second variable (latest month of update), the authors also assigned a score on a scale of 0 to 5 . Scores were given based on the month in which the update was made, but the authors assigned the highest score in cases where the update had been made in the week of the data collection (July 22 to 25, 2013). The coding scheme is as follows: latest update before March 2013, zero; update in April and March, 1; update in May, 2; update in June, 3; update in July, 4; and update between July 22 and 25,5 .

The authors calculated the total scores for each TD's website as described above and ranked them. They used these scores to conduct the website-feature analysis in the next section.

\section{WEBSITE-FEATURE ANALYSIS}

Looking at the sitting TDs of the four main political parties-i.e. Fianna Fáil (FF), Fine Gael (FG), Labour (Lab), and Sinn Féin (SF) — as a whole, the authors can see that one in six members, $17 \%$, are female. For the purposes of this study, the authors have defined the main political parties as those with three or more TDs currently sitting in the Dáil. Further, the total scores from across all the data follow roughly similar figures: female TDs contribute to $14 \%$ of the total scores, with their male counterparts being responsible for the remaining $86 \%$. Due to the vast disparity in the number of male and female TDs, this figure is of little surprise. 
By examining the IC of the 90 TDs' websites, the authors can determine whether each website contains at least one of the ten features included in the study. In addition, the authors can also determine whether any of the TD's websites contain all ten features. At the bottom end of the scale are eight websites that contain one to two features, while at the top end are ten websites that contain seven to eight features.

With reference to the data relating to IC, the authors found that those TDs at the top end of the scale communicate $25 \%$ more frequently than the average TD. These ten TDs whose websites contain seven to eight features are responsible for $17.2 \%$ of the total amount of online content of all TDs. In other words, 10 out of the 90 TDs studied are responsible for almost one-fifth of the total amount of IC contained in the data presented here. It is also worth noting that those TDs who are responsible for five to six features - what one may call closer to the average or representing the middle ground — are 46 in number and are responsible for $59.5 \%$ of the total IC. This means that just over $50 \%$ of TDs are responsible for fewer than $60 \%$ of the total IC.

With regard to the data relating to IT, the authors found that two TDs' websites do not contain any of these features while only one contains nine to ten features. Three TDs—-Joan Burton (Lab), ${ }^{6}$ Alex White (Lab), and Joe Higgins (Socialist Party, SP) — have websites that contain IT far and above their counterparts and are responsible for $7.3 \%$ of the total figures relating to this section of data. In another interpretation, these three TDs' websites contain $150 \%$ more IT than the average TD.

With regard to PAW, the authors measured the amount of updates that take place on each website over the five-month period during which the data were gathered. Information for five websites could not be accessed. Eleven websites out of the remaining 85 were not updated in the five months within which the data set was 
collected. Two websites had between 81-100 updates, and 74 websites had recently been updated, i.e. within the fifth month covered by the data set.

The authors found that $21.1 \%$ of the TDs have websites that have no activity at all, which is a significantly high number. These are termed 'dormants' in this paper. Those TDs performing at the top end are $100 \%$ more active than the average TD when these dormant TDs are included. When dormant websites are excluded, the top performing TDs—-Seán Crowe (SF) and Mattie McGrath (Independent, ID) - are 66.7\% more active than the average TD. Close behind Crowe and McGrath are Andrew Doyle (FG), Simon Harris (FG), Frank Feighan (FG), and Seán Kenny (Lab). Altogether, these six TDs are responsible for $13.2 \%$ of the total TDs' activities.

This finding lends the researchers some important insights when it comes to interpreting TDs' online profiles as a whole. With regards to IC, top performers have $33.33 \%$ more content than average TDs. There is hence room for improvement in terms of IC for average and below-average TDs. Regarding IT, Burton (Lab), White (Lab), and Higgins (SP) significantly outperformed those just below them, suggesting that average and below-average TDs can vastly improve how their constituents interact with them online. Finally, with regards PAW, there is cause for concern given the level of dormant TDs. Joan Burton (Lab), a top-performing TD in other areas, for example, contributes just $1.17 \%$ of the total amount of website activity of the TDs studied. This is interesting because $1.17 \%$ also happens to be the average contribution of each non-dormant TD to the overall data for website activities. While she is in the top TDs' cluster in other areas, she falls significantly short when it comes to website activities and can be best described as 'less than average' in this area. This, in turn, shows the researchers that most TDs' websites are used only for one-way traffic; however, it is worth noting that as the findings of Hoffmann and Suphan (2017); 
Hermans and Vergeer (2013); Kluver, Jankowski, Foot, and Schneider (2007); and Gulati and Williams (2007) have suggested, this is in keeping with political figures worldwide.

From the above data, one can make some interesting initial observations. Firstly, it is possible to describe certain politicians on the 'left' as performing significantly better than a large number of their counterparts on the 'right'. This is shown by the fact that Joe Higgins (SP) and Clare Daly (SP), ${ }^{7}$ the Socialist Party's two sitting members; Richard Boyd Barrett (PBP), the People Before Profit's only sitting $\mathrm{TD} ;^{8}$ and Labour's Burton (Lab) and White (Lab), all occupy positions in the top ten performing TDs. This finding is significant due to the fact that 95 of the Republic's total of 166 TDs are members of the two largest centre-right parties, Fine Gael and Fianna Fáil. It suggests that left-wing parties, with significantly fewer members in the Dáil, perform better than their opposite numbers in other parties.

This pattern echoes the findings of other studies. For instance, Vergeer, Hermans, and Sams (2013) looked at politicians running for the European Parliament (EP) elections and discovered that left parties are more prone to adopt new and advanced technologies than conservative parties. In the Irish context, centre-right politics is far more entrenched than the left-wing equivalent. One obvious reason is the impact of rural and nationalist values on Irish society in the past. Fine Gael Youth is the largest youth movement in the state, and Fianna Fáil is not too far behind. This level of organization among the two largest right-wing parties in turn forces those on the left to adopt new methods of getting their message across, in this case compensating by performing far and above the right in Web 2.0 usage.

Secondly, in recent years, there has been a move away from the traditional use of websites to disseminate information and interact with constituents, due to the 
advent of other Internet-based methods of communication. For instance, Barack Obama's 2008 election was described at the time as the first 'YouTube election', given the non-traditional means of interaction employed by his election team for reaching voters (Kenski, Hardy, \& Jamieson, 2010). Similarly, given that even a high performer like Joan Burton (Lab) drops significantly when her website activity is observed, it may be possible for the researchers to assume that this was due to the development of social media outlets such as Facebook, YouTube, and Twitter. It is thus imperative that the authors also examine and compare TDs' website activities with their other social media activities. This will be dealt with in the next section.

Finally, there seems to be a direct correlation between geographical location and the overall data employed in this study. For example, with IC, as seen in the previous section, ten TDs received a score of 4/5 in this area: Richard Boyd Barrett (PBP), Joan Burton (Lab), Joan Collins (United Left Alliance, ULA), Lucinda Creighton (FG), ${ }^{9}$ Alan Farrell (FG), Brian Hayes (FG), Anthony Lawlor (FG), Nicky McFadden (FG), ${ }^{10}$ Catherine Murphy (Ind), and Alex White (Lab). Similarly, eight TDs received a score of 1/5: John Browne (FF), Eric Byrne (Lab), Michael Colreavy (SF), Jimmy Dennihan (FG), Heather Humphreys (FG), SeánKenny (Lab), Michael Moynihan (FF), and Ruairi Quinn (Lab). What is most interesting about this is that all the top performers for IC represent either constituencies in Dublin or constituencies in the surrounding counties that can be considered 'commuter' areas for the capital. These areas traditionally have some of the highest rates of Internet usage in the state. Similarly, five of the eight worst performing TDs in this section are from rural areas, or areas that are traditionally associated with low levels of Internet usage. Surprisingly enough, it is worth noting that two of the TDs that are not from rural 
areas, Kenny (Lab) and Quinn (Lab), represent constituencies in Dublin and are members of the Labour Party.

\section{DISCUSSION}

The empirical analysis leads the researchers to suspect that some of the TDs' online activities have been transformed from websites to other Internet-based methods of communication; it is, therefore, important to compare TDs' performance across websites, Twitter, Facebook, and other social media platforms.

In an interview with the Fianna Fáil press officer, Eoin Weldon commented that most of his party's TDs have set up Twitter and Facebook accounts for elections. But the party also encourages their politicians to use these platforms after elections. For public policies, TDs must follow the party line in their online expression. This kind of information is also accessible already in the party's press releases. TDs themselves know that they should not veer away from the party line. For issues that are not yet policies, such as the heated debate over abortion, TDs may express personal opinions. In addition, TDs are encouraged to tweet less political messages, such as wishing people success for sporting events. This kind of message is also important as it is a link to the public and shows politicians' human side. ${ }^{11}$

Due to limited resources, however, the authors do not have a complete dataset of the TDs' Twitter and Facebook activities for comprehensive comparison. The authors have hence only selected some TDs for further observation. Based on the scores given and considering each criterion for evaluating websites individually, the authors selected the best and the worst webpages and created the following list of 30 TDs (see Table 1). 


\begin{tabular}{|c|c|c|}
\hline & The best websites & The worst websites \\
\hline $\begin{array}{l}\text { Information } \\
\text { content (IC) }\end{array}$ & $\begin{array}{l}10 \text { TDs' websites have a } \\
\text { score of } 4 \text { out of } 5 \text { : } \\
\text { Richard Boyd } \\
\text { Barret (PBP), Joan } \\
\text { Burton (Lab), Joan } \\
\text { Collins (ULA), Lucinda } \\
\text { Creighton (FG), Alan } \\
\text { Farrell (FG), Brian Hayes } \\
\text { (FG), Antony Lawlor } \\
\text { (FG), Nicky McFadden } \\
\text { (FG), Catherine Murphy } \\
\text { (Ind), and Alex White } \\
\text { (Lab). }\end{array}$ & $\begin{array}{l}8 \text { TDs' websites have a score of } 1 \text { out } \\
\text { of 5: John Browne (FF), Eric Byrne } \\
\text { (Lab), Michael Colreavy (SF), } \\
\text { Jimmy Deenihan (FG), Heather } \\
\text { Humphreys (FG), Seán Kenny (SF), } \\
\text { Michael Moynihan (FF). } \\
\text { and Ruairi Quinn (Lab). }\end{array}$ \\
\hline $\begin{array}{l}\text { Interaction } \\
\text { tool (IT) }\end{array}$ & $\begin{array}{l}1 \text { TD, Joan Burton (Lab), } \\
\text { has a score of } 5 \text { out of } 5 \text {. }\end{array}$ & $\begin{array}{l}2 \text { TDs have a score of zero: } \\
\text { Frank Feighan (FG) and Pat } \\
\text { Deering (FG). }\end{array}$ \\
\hline $\begin{array}{l}\text { Political } \\
\text { activity on } \\
\text { the website } \\
\text { (PAW) }\end{array}$ & $\begin{array}{l}2 \text { TDs have a score of } 5 \\
\text { out of } \\
\text { 5: Seán Crowe (SF) } \\
\text { and Mattie McGrath } \\
\text { (Ind). }\end{array}$ & $\begin{array}{l}11 \text { TDs received a score of zero: Niall } \\
\text { Collins (FF), Michael Colreavy (SF), } \\
\text { Simon Coveney (FG), Paschal } \\
\text { Donohoe (FG), Phil Hogan (FG), } \\
\text { Michael Moynihan (FF), } \\
\text { Aengus Ó Snodaigh (SF), } \\
\text { Ruari Quinn (Lab), Brendan } \\
\text { Ryan (Lab), Alan Shatter (FG), and }\end{array}$ \\
\hline
\end{tabular}


\begin{tabular}{|l|l|} 
& Brian Walsh (FG). \\
\hline
\end{tabular}

Table 1. Features of Irish parliamentarians' websites

The Twitter activities of these 30 TDs were observed and data were collected from August 19 to 23, 2013. Facebook data were collected from August 26 to 30, 2013. Some initial observations can be made from these data. The authors found a mixed picture of TDs' usage across websites, Twitter, and Facebook. Ruairi Quinn (Lab), for instance, has one of the poorest websites, with 0.5 as his average score for IC, IT, and PAW. He has no Facebook account and no tweets from his Twitter account. Web 2.0 apparently is not his platform.

Alan Farrell (FG), in contrast, has a good overall score of 3.5 and seems to be the most active on Twitter with 11,805 tweets (as of August 30, 2013). His Facebook friends, however, are not many: 57 as of August 30, 2013. Another example is Heather Humphreys (FG). She performed well in terms of activities on her website as well as her Facebook activities - she updates her Facebook account frequently. But she does not use Twitter.

Another interesting case is that of Joan Burton (FG). She uses Facebook and she has a commanding mass of Twitter followers at 9,067 , but she does not seem to be active in any actual tweeting. The same pattern can be observed in her usage of her personal website: it is over-tooled, but she has less than average engagement on her website.

Most selected TDs under observation do not exploit all the functions and potentials of social media. TDs use Facebook fan pages, but not personal pages. This makes it easier for the page to be managed by staff. Also, they mostly merely replicate the information already posted on Twitter and websites. This pattern is 
similar to what the researchers have observed in their website performance. The interactive and participatory features of Web 2.0 are not fully exploited.

It is vital to note, however, that the authors only compared 30 selected TDs: this can give the researchers some indication, but is surely not a holistic picture of Irish parliamentarians' Twitter and Facebook activities. If the resources allowed, the authors could have had a comprehensive dataset to check if some TDs have directly adopted a social media platform, such as Twitter or Facebook or other platforms, to replace their websites. One politician who is well-known in Ireland for his heavy reliance on the power of the Internet to garner visibility, popularity and electoral support is independent TD Luke Flanagan (Ind) of Roscommon. He does not extensively use posters or other expensive offline campaign methods that other competing candidates would have done. He does not have a website at all, either. Rather, he uses Twitter and Facebook to shape the image that he is supportive of radical ideas and fresh policies on drugs. The media fed off the styling of his beard and shaving of his head along with the illustrations of cannabis plants in his campaigns to portray him as being a maverick. However, despite this negative coverage, he was able to use it to gain the attention of the press and media and he played well the role of an outsider in the political sphere of Ireland. In 2014, he was elected to the European Parliament.

\section{CONCLUSION}

Irish parliamentarians embed themselves online mainly to catch up with trends in the cyber age. Websites allow them to market themselves and increase visibility. But given that the offering of information is the prime aim, their usage of the Internet is still largely based on the paradigm of Web 1.0. This pattern is similar to what Lilleker 
and Jackson (2010 and 2013) have found in the UK and, more recently, by Hoffmann and Suphan (2017) in Germany where "despite potential benefits, empirical analyses show that politicians tend to shy away from an active engagement of online audiences" (p. 1468). A more accurate way to depict this phenomenon is that Irish politicians' Internet usage is actually in the mode of Web 1.5 in which some interactive and participatory space is generated with the idea that the cyberspace should encourage citizen participation. But actual practice shows that improvements can still be made. Also, as conventional variables such as party affiliation (i.e. left/right cleavage) and geographic variation still have an influence on TDs' website performance, one can conclude that ICTs do not really change the way Irish politics are played traditionally. Politics in the mode of Web 1.5 is primarily affected by pre-Internet structures and forces. The Irish experience is in line with various other studies around the world, such as in Portugal (Cunha \& Seiceira, 2017), New Zealand (Ross, Fountaine, \& Comrie, 2015), Italy (Vaccari, 2008), and Finland (Strandberg, 2013). The lesson of Denmark (Sørensen, 2016) may point to a different future but, for the moment, the main realm of Irish politicians' interaction with the public is still outside the cyberspace.

\section{ACKNOWLEDGEMENTS}

The authors would like to thank Christopher Bacani, Luca Caruso, Lara Fote, Valentine Kearney, and Aiman Temirova for their research assistance.

\section{REFERENCES}

Abney, R., Adams J., Clark, M., Easton, M., Ezrow, L., Kosmidis, S., \& Neundorf, A. (2013). When does valence matter? Heightened valence effects for governing parties during election campaigns. Party Politics, 19(1), 61-82. 
Albrecht, S., Lübcke, M., \& Hartig-Perschke, R. (2007). Weblog campaigning in the German Bundestag election 2005. Social Science Computer Review, 25(4), 504520.

Barber, J. D. (1965) The lawmakers: Recruitment and adaptation to legislative life. New Haven: Yale University Press.

Bax, M. (1976). Harpstrings and confessions: Machine style politics in the Irish republic. Amsterdam: Van Corcum.

Boyd Barrett, R. (2014). People before Profit Alliance as part of the United Left Alliance. Official Website of Richard Boyd Barrett TD. Retrieved July 21, 2014, from https://richardboydbarrett.ie/pbpula/

Butler, P., \& Collins, N. (2001). Payment on delivery: Recognising constituency service as political marketing. European Journal of Marketing, 35(9/10), 1026-37.

Chen, Y. W. (2012). Internet and interest articulation in China: A theoretical reexamination. First Monday, 17(1-2). Retrieved from http://firstmonday.org/ojs/index.php/fm/article/view/3310/3135

Chen, Y. W. (2013). Bringing a network perspective to Chinese Internet studies: An exploratory analysis. Journal of Chinese Political Science, 18(4), 355-374.

Chubb, B. (1963). Going about persecuting civil servants: The role of Irish parliamentary representatives. Political Studies, 11(3), 272-286.

Clare, D. (2012). Clare Daly confirmation of resignation. Official Website of Clare Daly TD. Retrieved July 4, 2014, from http://claredaly.ie/clare-daly-confirmationof-resignation/

Collins, N. (2004). Parliamentary democracy in Ireland. Parliamentary Affairs, 57(3), 601-612.

Collins, N., \& Butler, P. (2001). Cute hoors as local heroes: Politicians and public service delivery. Irish Journal of Management, 22(1), 113-126.

Collins, N., \& Cottey, A., (2012). Understanding Chinese politics. Manchester: Manchester University Press.

Cunha, C., \& Seiceira, F. (2017). Information and communication technologies, citizens, and parliament in Portugal: The continued e-democracy gap and lessons from the Obama experience. In P. Meil, \& V. Kirov (Eds.), Policy implications of virtual work (pp. 165-197). London: Springer.

Esaiasson, P., \& Narud, H. M. (Eds.). (2013) Between-election democracy: The representative relationship after election data. Colchester: ECPR Press.

Farrell, D. M., \& Webb, P. (2000). Political parties as campaign organizations. In R. Dalton, \& M. Wattenberg (Eds.), Parties without partisans: Political change in advanced industrial democracies (pp. 102-128). Oxford: Oxford University Press.

Fuchs, C. (2017). Social media: A critical introduction. London: Sage.

Gulati, G. J., \& Williams, C. B. (2007). Closing the gap, raising the bar: Candidate web site communication in the 2006 campaigns for Congress. Social Science Computer Review, 25(4), 443-465.

Hall, L., Strandberg, T., Pärnamets, P., Lind, A., Tärning, B., \& Johansson, P. (2013). How the polls can be both spot on and dead wrong: Using choice blindness to shift political attitudes and voter intentions. PLoS ONE, 8(4), doi:10.1371/journal.pone.0060554

Harfoush, R. (2009). Yes we did! An inside look at how social media built the Obama brand. Berkeley, CA: New Riders.

Harris, P. (2000). To spin or not to spin, that is the question: The emergence of modern political marketing. The Marketing Review, 2, 35-53. 
Hermans, L., \& Vergeer, M. (2013). Personalization in e-campaigning: A crossnational comparison of personalization strategies used on candidate websites of 17 countries in EP elections 2009. New Media and Society, 15(1), 72-92.

Hoffmann, P., \& Suphan, A. (2017). Stuck with 'electronic brochures'? How boundary management strategies shape politicians' social media use. Information, Communication and Society, 20(4), 551-569.

Jensen, M. (2017). Social media and political campaigning: Changing terms of engagement? The International Journal of Press/Politics, 22(1), 23-42.

Kenski, K., Hardy, B. W., \& Jamieson, K. H. (2010). The Obama victory: How media, money, and message shaped the 2008 Election. New York: Oxford University Press.

Kluver, R., Jankowski, N., Foot, K., \& Schneider, S. M. (Eds.). (2007). The Internet and national elections: A comparative study of web campaigning. New York: Routledge.

Lilleker, D. G., \& Jackson, N. A. (2010). Towards a more participatory style of election campaigning: The impact of Web 2.0 on the UK 2010 general election. Policy and Internet, 2(3), 69-98.

Lilleker, D. G., \& Jackson, N. A. (2013). Reaching inward not outward: Marketing via the Internet at the UK 2010 general election. Journal of Political Marketing, 12(2-3), 244-261.

Liston, V., Harris, C., \& O'Toole, M. (2014). Bridging normative democratic theory and Internet technologies: A proposal for scaling citizen policy deliberations. Policy and Internet, 5(4), 462-485.

Lynch, K., \& Hogan, J. (2012). How Irish political parties are using social networking sites to reach generation $\mathrm{Z}$ : An insight into a new online social network in a small democracy. Irish Communications Review, 13, 83-98.

MacConnell, E. (2014, March 25). Fine Gael TD Nicky McFadden dies, aged 51. The Irish Times. Retrieved August 22, 2014, from http://www.irishtimes.com/news/politics/fine-gael-td-nicky-mcfadden-dies-aged51-1.1737618

Marsh, M., Farrell, D., \& McElroy, G. (2017). A conservative revolution? Electoral change in twenty-first century Ireland. New York: Oxford University Press.

Marsh, M., \& Mikhaylov, S. (2014). A conservative revolution: The electoral response to economic crisis in Ireland. Journal of Elections, Public Opinion and Parties, 24(2), 160-179.

Martin, S. (2013). Is all politics local? The role-orientation of Irish parliamentarians towards foreign policy, Irish Political Studies, 28(1), 114-129.

McGee, H. (2014, July 4). Joan Burton elected as $11^{\text {th }}$ leader of Labour Party. The Irish Times. Retrieved July 4, 2014, from http://www.irishtimes.com/news/politics/joan-burton-elected-as-11th-leader-oflabour-party-1.1855454

McGraw, S. (2016). Ideological flexibility and electoral success: An analysis of Irish party competition. Irish Political Studies, 31, 461-482.

Murphy, L. (2013). The modernization of Irish political campaigning: The 2011 general election (MSc dissertation series). London School of Economics and Political Science, London.

Murphy, M. C. (2013). At home in the new house: A study of Ireland's first-time TDs. London: Hansard Society.

O'Connor, T. (2014, June 9). What can come of the leftward movement in the Irish local and Euro elections? Irish Left Review. Retrieved July 4, 2014, from 
http://www.irishleftreview.org/2014/06/09/leftward-movement-irish-local-euroelections/

O'Leary, E. (2011). The constituency orientation of modern TDs. Irish Political Studies, 26(3), 329-343.

Ott, B. (2017). The age of Twitter: Donald J. Trump and the politics of debasement. Critical Studies in Media Communication, 34(1), 59-68.

Ross, K., Fountaine, S., \& Comrie, M. (2015). Facing up to Facebook: Politicians, publics and the social media(ted) turn in New Zealand. Media, Culture and Society, 37(2), 251-269

Sacks, P. M. (1976). The Donegal mafia: An Irish political machine. London: Yale University Press.

Samodra, A. B., \& Minsani, M. (2013). Examining the influence of social norms on the intention to use social networking media: A study of generation $\mathrm{Z}$ in Indonesia. GSTF Journal on Computing, 3(1), 127-130.

Scacco, J., \& Coe, K. (2017). Talk this way: The ubiquitous presidency and expectations of presidential communication. American Behavioral Scientist, 61(3). Retrieved from http://journals.sagepub.com/doi/full/10.1177/0002764217704321

Schlozman, K. L., Verba, S., \& Brady, H. E. (2010). Weapon of the strong? Participatory inequality and the Internet. Perspectives on Politics, 8(2), 487-509.

Sørensen, M. P. (2016). Political conversations on Facebook - The participation of politicians and citizens. Media, Culture and Society, 38(5), 664-685.

Standage, T. (2013). Writing on the wall: Social media - The first 2,000 years. London: Bloomsbury.

Strandberg, K. (2013). A social media revolution or just a case of history repeating itself? The use of social media in the 2011 Finnish parliamentary elections. New Media and Society, 15(8), 1329-1347.

Vaccari, C. (2008). Research note: Italian parties' websites in the 2006 elections. European Journal of Communication, 23(1), 69-77.

Vergeer, M., Hermans, L., \& Cunha, C. (2013). Web campaigning in the 2009 European Parliament elections: A cross-national comparative analysis. New Media and Society, 15(1), 128-148.

Vergeer, M., Hermans, L., \& Sams, S. (2013). Online social networks and microblogging in political campaigning: The exploration of a new campaign toll and a new campaign style. Party Politics, 19(3), 477-501.

Vromen, A. (2017). Digital citizenship and political engagement: The challenge from online campaigning and advocacy organisations. Basingstoke: Palgrave Macmillan UK.

Wicklund, R. A., \& Brehm, J. W. (1976). Perspectives on cognitive dissonance. Hillsdale, NJ: Lawrence Erlbaum.

Williamson, A. (2009). The effect of digital media on MPs' communication with constituents. Parliamentary Affairs, 62(3), 514-527.

\section{NOTES}


1. Referred to in some election studies as 'between-election'. See, for example, Esaiasson and Narud (2013).

2. The term Ireland will be used here to refer to the jurisdiction of the Republic of Ireland unless stated otherwise.

3. Fine Gael 28\% and Fianna Fáil 27\%, in Sunday Times Behaviour and Attitudes opinion poll, published May 14, 2017. Retrieved from https://www.rte.ie/news/2017/0513/874951-opinion-poll/

4. In 2011, the year in which the parliamentarians studied here were elected, 45 sitting TDs lost their seats and 39 incumbents decided not run again.

5. Taken here as born between 1990 and 2004, though definitions in the social media literature differ.

6. Joan Burton was Minister for Social Protection at the time of the research and on July 4, 2014 became leader of the Labour Party.

7. Clare Daly was elected as a Socialist Party TD in 2011. She resigned from the party on August 31, 2012, re-designating herself as a United Left Alliance TD.

8. A number of the left-leaning TDs in the Dáil are part of the United Left Alliance (ULA), which is made up of PBP and others. Joan Collins was an Indepedent but contested in the 2011 General Election as PBP. She left PBP in 2013 and now operates under the ULA. Hence, Richard Boyd Barret is the PBP's only sitting TD in the data.

9. No longer FG.

10. Died on March 25, 2014.

11. Interview with Eoin Weldon, Fianna Fáil press officer, August 6, 2013. 